\title{
Lower Tropospheric Ozone Measurements by Light Aircraft Equipped with Chemiluminescent Sonde
}

\author{
I. G. McKendRy And D. G. STEYN \\ Atmospheric Science Programme, Department of Geography, University of British Columbia, Vancouver, British Columbia, Canada \\ S. O'KANE \\ Levelton Associates, Richmond, British Columbia, Canada \\ P. ZAWAR-REZA \\ Department of Geography, University of Canterbury, Christchurch, New Zealand \\ D. HEUFF \\ Department of Mathematics, University of Canterbury, Christchurch, New Zealand
}

(Manuscript received 11 October 1996, in final form 30 May 1997)

\begin{abstract}
Novel use of a commercial, battery-powered, chemiluminescent ozonesonde on a light aircraft is described. This fast-response instrument, originally designed for balloon deployment into the stratosphere, is light, inexpensive, robust (reuseable), reliable, and accurate. Integration with other lightweight components (data logger, global positioning system, pressure, temperature, and humidity sensors) renders the system suitable for use in a light (rental) aircraft with no modification of the aircraft required. The system is well suited to routine reconnaissance and vertical profiling in regions of complex terrain, and with well-designed field studies, mass budget analyses are feasible. The application and validation of the system is described for the Lower Fraser Valley, British Columbia, a region of complex coastal terrain where photochemical smog is a significant problem in the summer months.
\end{abstract}

\section{Introduction}

Full understanding of the air pollution meteorology of any region can only be based on consideration of the entire lower troposphere where the processes of transport and dispersion take place. This has been highlighted in intensive field campaigns in regions where photochemical air pollution is a problem. For example, studies in northeastern North America (e.g., Clarke and Ching 1983), the Swiss Alps (Neu et al. 1994), the Los Angeles Basin (McElroy and Smith 1993), and Vancouver, British Columbia (McKendry et al. 1997), all describe environments characterized by horizontal transport of precursors and photochemical oxidants to remote/rural sites and vertical down-mixing of pollutants from residual or elevated layers. In such circumstances, data from standard surface monitoring networks may misrepresent the

Corresponding author address: Ian G. McKendry, Department of Geography, University of British Columbia, \#217-1984 West Mall, Vancouver, BC V6T 1Z2, Canada.

E-mail: ian@geog.ubc.ca true vertical and spatial distribution of pollutants in a region and, furthermore, are of limited use in developing and validating photochemical models used to develop abatement strategies. Simple methods of spatial survey and vertical profiling are therefore of utmost importance in defining the dimensions of regional photochemical pollution problems (perhaps as a prelude to surface network design) as well as providing data for both development of parameterizations of vertical mixing processes and model validation.

This paper describes application of a commercial, battery-powered, chemiluminescent sensor for aircraft measurements of ozone $\left(\mathrm{O}_{3}\right)$ in the lower troposphere. This fast-response instrument, originally designed for balloon deployment into the stratosphere, is light, cheap, robust (reuseable), reliable, and accurate. Data acquisition is by standard data logger and notebook computer. These qualities render the system suitable for use in a light (rental) aircraft with no modification of the aircraft required. Consequently, the system offers distinct advantages over other airborne systems that are often expensive and require large modified 
aircraft. Hence, it is particularly attractive for both routine reconnaissance and intensive research campaigns. In addition to describing the instrumentation, its response characteristics, installation on the aircraft, and postflight corrections, validation of the method by comparison with surface monitors and tethered ozonesondes will be presented. Finally, application of the system will be demonstrated in the context of the Lower Fraser Valley (hereafter referred to as LFV), British Columbia, a region of complex coastal terrain where photochemical smog is a significant problem in the summer months.

\section{Methods}

\section{a. Measurements of ozone in the lower troposphere}

Several techniques have been used to measure ozone concentrations above the earth's surface. These include ground-based and airborne remote sensing using laser technology (Schiff et al. 1994), deployment of bulky commercial UV photometers or chemiluminescent sensors (with some modification to account for pressure effects) on dedicated research aircraft (Kondo et al. 1987; Beekman et al. 1995), and vertical profiling using lightweight electrochemical sensors supported by balloons (Pisano et al. 1997) and kites (Balsey et al. 1994). Ozone flux measurements have also been made from aircraft over a variety of ecosystems (e.g., Ritter et al. 1994) using chemiluminescent sensors based on the design of Pearson and Stedman (1980). Low-cost, lightweight electrochemical sensors (e.g., the ECC, BrewerMast, and Atmospheric Instrumentation Research sondes) have been traditionally used for ozone soundings (Beekman et al. 1995). However, recently, a cheap, lightweight $(0.8 \mathrm{~kg})$ chemiluminescent instrument has become available for balloon deployment in the troposphere and stratosphere (Schurath et al. 1991; Güsten et al. 1992). It is this commercially available instrument that forms the basis of the airborne system described here.

\section{b. Ozone sensor}

Specifications of the GFAS (Gesellschaft Für Anglewandte Systemtechnik) OS-B-2 ozonesonde are described in Schurath et al. (1991) and Güsten et al. (1992). The instrument is based on the principle of surface chemiluminescence due to the reaction of ozone with an organic dye (Coumarin 47). The organic dye is incorporated into the outer layer of a replaceable, commercially available chemiluminescent target. The intensity of chemiluminescence is measured by a side-window photomultiplier tube and converted into an analog output signal. A crucial component of the ozonesonde is a miniaturized fan that ensures sufficient flow rate to maintain the instrument in a regime, whereby chemiluminescent intensity is independent of flow rate and is proportional only to the absolute concentration of ozone in the sample (the "flow-independent" regime). The instrument has a specified accuracy of $\pm 5 \%$ and shows good agreement with Brewer-Mast electrochemical sondes in profile intercomparisons extending into the stratosphere (Speuser et al. 1989). Before deployment of the ozonesonde, a "preozonization" procedure ensures activation of the target and the maximum sensitivity of the instrument. During this procedure, the ozonesonde is exposed to concentrations of 100-150 ppb of ozone for $1-1.5 \mathrm{~h}$ from a custom-designed GFAS "control unit" (ozone generator). Once preozonization is completed, the instrument is calibrated (this requires the availability of a secondary standard ozone monitor) and the sonde is then ready for use. The lifetime of the chemiluminescent targets is approximately 6 months in storage and $2000 \mathrm{ppb}$ h once activated. The instrument itself is extremely robust and therefore, provided that targets are replaced periodically, it may be used repeatedly.

\section{c. Preflight calibration and postflight corrections}

After preozonization the OS-B-2 is calibrated by measuring the output voltage at a known concentration (produced by the ozone generator) and measured by reference monitor.

Once calibrated, the sensitivity of the OS-B-2 is dependent upon temperature, pressure, and humidity (Schurath et al. 1991). With respect to temperature, the OS-B-2 is equipped with a heater that maintains the temperature of the chemiluminescent target at either $0^{\circ} \mathrm{C}$ (preferable for profiles through the troposphere and stratosphere) or $30^{\circ} \mathrm{C}$ (preferable for boundary layer measurements). Provided that the instrument is calibrated with heater at the $30^{\circ} \mathrm{C}$ setting, no temperature corrections are required during flights within the lower troposphere. Decreasing ambient pressure will lead to higher sensitivity values for the instrument. The correction factor $F_{p}$ for the pressure dependence of the sensitivity is given by

$$
F_{p}=\left(1-0.63 \log \frac{p_{\text {meas }}}{p_{\text {cal }}}\right),
$$

where $p_{\text {cal }}$ is the ambient air pressure during calibration and $p_{\text {meas }}$ is the ambient pressure during subsequent measurements. For measurements within the planetary boundary layer (PBL), $F_{p}$ may be of order 0.97 , which represents only a $3 \%$ change in sensitivity from calibration (usually conducted at the surface). Consequently, it too can be neglected. Finally, the sensitivity of the OS-B-2 changes with gross changes in absolute humidity as found between the troposphere and stratosphere. However, for measurements in the PBL this effect is also negligible. In summary, when deployed in the PBL, corrections to the OS-B-2 signal for pressure, temperature, and humidity effects are small and can be ne- 
TABLE 1. Instruments required, their weight $(\mathrm{kg})$, and approximate cost $(\$ \mathrm{CDN})$. Note that costs are approximate only; an ozone monitor is required for calibration procedures, and temperature and humidity sensors may be added to the system.

\begin{tabular}{lcr}
\hline \hline \multicolumn{1}{c}{ Instrument } & Weight (kg) & Cost (approx, \$CDN) \\
\hline OS-B-2 Ozonesonde-GFAS & 0.8 & 2000 \\
VM-K-2 control unit (ozone generator)_GFAS & 6.0 & 5000 \\
Intellisensor II pressure sensor_-Model AIR-AB-2A & 0.3 & 500 \\
CR10X Data Logger & 0.8 & 2000 \\
Power supply_-12-V gel cell & 8.0 & 80 \\
GPS-e.g., Trimble SveeSix Series (including magnetic mount antenna, & 0.4 & 3000 \\
baud rate converter, interface cable) & & \\
\hline
\end{tabular}

glected. Outside the PBL these effects become significant and must be corrected for.

\section{d. Airborne system configuration}

In adapting the GFAS OS-B-2 ozonesonde to deployment in a light aircraft (in this case, a single-engine Cessna 172), the following critical concerns were studied.

\section{1) ENSURE AN UNCONTAMINATED SAMPLE}

To avoid mounting the system on the aircraft exterior (an advantage when using rental aircraft), air is funnelled into the instrument that is clamped to the rear of the cockpit via Teflon intake tubing extended through the open cockpit window. The intake is attached to the left-hand side of the cockpit window within the propwash and away from the aircraft exhaust on the right-hand underside of the aircraft. This ensures a well-mixed, uncontaminated sample. Comparisons with independent measurements during flight are described below and suggest negligible contamination of the sample.

\section{2) Maintain Flow Rates IN the flow INDEPENDENT REGIME}

In connecting the OS-B-2 to Teflon tubing, the efficiency of the miniaturized pump is severely compromised by the aerodynamic resistance of the tubing. However, during flight, air is forced through the tubing into the instrument. To ensure adequate, but not excessive, flow rates through the instrument, the intake tubing was arranged in a bypass mode that permitted the ozonesonde to bleed off a portion of the flow into the aircraft. Wind tunnel tests with this configuration showed that the critical flow rate of $151 \mathrm{~min}^{-1}$, which is required to maintain the instrument in the flow-independent regime at lower tropospheric pressures was reached at aircraft speeds of $22 \mathrm{~m} \mathrm{~s}^{-1}$, well below those reached during takeoff, vertical profiling maneuvers $\left(35 \mathrm{~m} \mathrm{~s}^{-1}\right)$, and horizontal flight $\left(50 \mathrm{~m} \mathrm{~s}^{-1}\right)$.

\section{3) ENSURE SUFFICIENT RESOLUTION AT AIR SPEEDS} OF APPROXIMATELY $50 \mathrm{M} \mathrm{S}^{-1}$

With a specified time constant of $1 \mathrm{~s}$ for the OS-B2 , the aircraft in horizontal flight can resolve fluctuations on wavelengths of approximately $100 \mathrm{~m}$. This is deemed sufficient for the purposes discussed here (basic aerial reconnaissance). For vertical profiling, where aircraft vertical velocity is of the order of $3 \mathrm{~m} \mathrm{~s}^{-1}$, fluctuations at wavelengths of approximately $6 \mathrm{~m}$ are resolvable.

\section{e. System components and costs}

In addition to the OS-B-2 ozonesonde, the system includes components for data acquisition, positioning, and monitoring of related meteorological variables. These components are listed in Table 1 with approximate costs. A high-resolution digital barometer is used for pressure measurements that may be used to correct ozone measurements (see above) as well as establish aircraft altitude. Air temperature is measured by thermistor at both the air intake and within the cockpit. Aircraft location may be determined by reference to preestablished landmarks or by commercial global positioning systems (GPSs). A GPS compatible with the Campbell Scientific CR10X data logger is listed in Table 1. All variables, including position data, are logged and stored at 3-s intervals on the data logger. A laptop computer may be used during flights to monitor all variables, although this is not necessary. With available memory in the CR10X (128K) and with a 3-s sampling rate, flights may extend for $2.5 \mathrm{~h}$ without downloading from data logger to computer. A $12-\mathrm{V}$ gel cell battery is used to power both the data logger and OS-B-2.

\section{Field validation}

During operations in the LFV, validation of aircraft measurements was based on two sources of independent data.

\section{a. Comparisons with surface monitors and electrochemical ozonesondes}

Figure 1 shows an ensemble of comparative measurements on occasions when the aircraft (at an altitude 


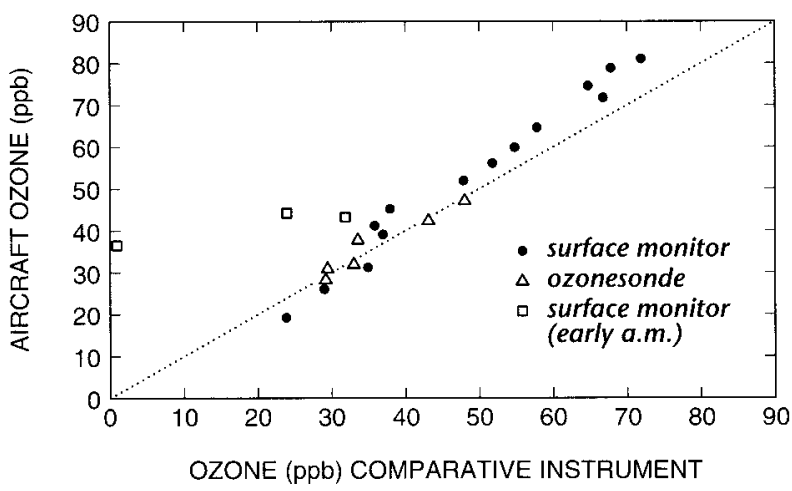

FIG. 1. Comparison of midboundary layer measurements with aircraft-mounted OS-B-2 and surface monitors directly below. Comparisons with an Atmospheric Instrumentation Research electrochemical sonde flown on a tethered balloon at approximately the same time, height, and location as the aircraft are also shown.

of $\sim 500 \mathrm{~m}$ ) flew directly over surface monitors or past a tethered ozonesonde (Atmospheric Instrumentation Research Inc.) at the same elevation. These observations are derived from 5 days, reflecting the range of ozone concentrations typically encountered in the LFV. With the exception of the labelled early morning flights on 13 August 1994, all observations are associated with an afternoon convective boundary layer. For afternoon conditions, agreement between surface monitors and the airborne sensor is generally good $\left(r^{2}=0.98\right)$. Aircraft concentrations are generally higher than surface concentrations due to the effects of surface deposition. This effect is most pronounced on the morning of 13 August when, at the surface, concentrations were very low (due to deposition overnight) compared to the relatively high concentrations persisting within the residual mixed layer aloft overnight (McKendry et al. 1997). As expected, the agreement between observations at the same elevation (electrochemical ozonesonde on tethered balloon versus aircraft) is good, with no apparent bias.

\section{b. Simultaneous profiles}

A more rigorous test of the accuracy, and ability of the OS-B-2 to resolve ozone gradients during flight, is provided by simultaneous, collocated ozone profiles by tethersonde-ozonesonde and slowly spiraling aircraft. In the case shown in Fig. 2, the aircraft spiralled around the tethersonde during midafternoon in typical nonepisode conditions. In this case, the mean difference between instruments was small and clearly demonstrates the ability of the airborne OS-B-2 to capture the finescale vertical ozone structure in the PBL (e.g., the increase in concentrations evident at $450 \mathrm{~m}$ ).

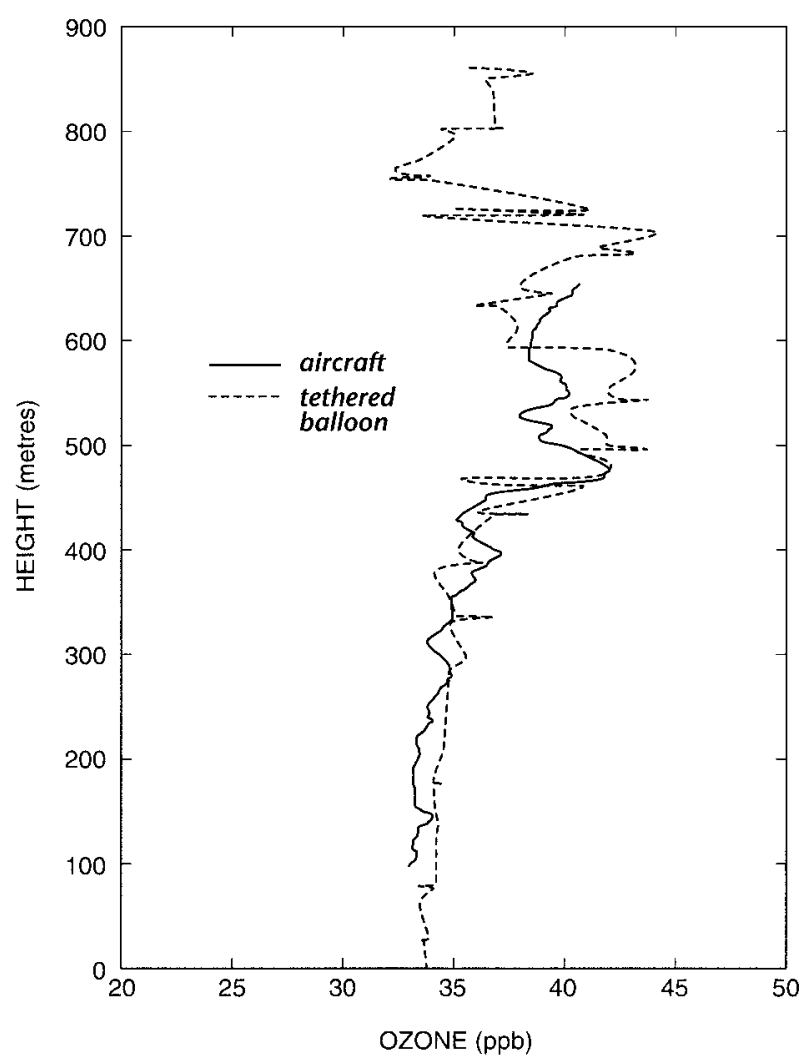

FIG. 2. Simultaneous, collocated afternoon boundary layer profiles from a tethered Atmospheric Instrumentation Research electrochemical sonde and the slowly spiraling aircraft.

\section{Application in the Lower Fraser Valley}

\section{a. Background}

The LFV of southwestern British Columbia (Fig. 3a) is one of three areas in Canada where the National Ambient Air Quality Objective for ozone of $82 \mathrm{ppb}$ (hourly) is frequently exceeded during the summer months. Such events are usually associated with stagnating anticyclonic situations when local thermotopographic circulations such as sea/land and mountain/valley winds are well developed, and pollutants emanating from greater Vancouver (Fig. 3a) are generally transported eastward (McKendry 1994; Steyn and McKendry 1988). Recent studies show that during such episodes, pollutants are often transported beyond the existing surface monitoring network within the LFV (e.g., into tributary valleys) and may also become trapped in layers aloft where they may persist or become mixed to ground (McKendry et al. 1997). Understanding the vertical and horizontal distribution of ozone is therefore essential to impact assessment, modeling, and mass budget analyses. The following examples demonstrate how an airborne sensor may be used to complement standard surface-based measurements. 

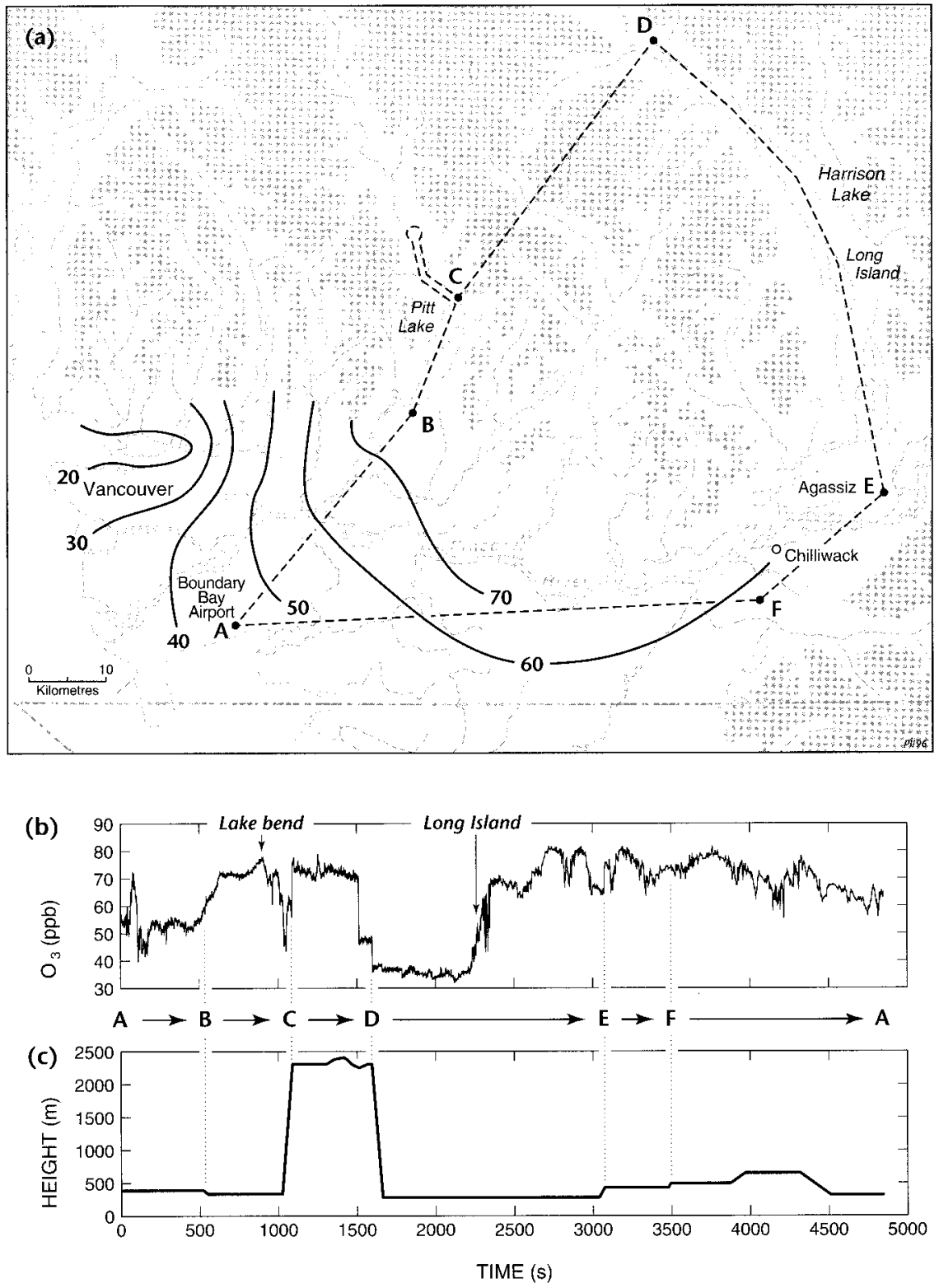

FIG. 3. Observations on 19 July 1995 in the LFV and tributary valleys. (a) Map showing flightpath and 1500 PST ozone isopleths (ppb) derived from surface observation network, (b) aircraft-derived ozone concentrations along the flight path, and (c) aircraft altitude during flight.

\section{b. Horizontal surveys and vertical profiling}

On 19 July 1995, ozone concentrations in the central LFV reached 72 ppb under warm, anticyclonic conditions. Moderate $\left(4-5 \mathrm{~m} \mathrm{~s}^{-1}\right)$ west to southwesterly winds prevailed during the afternoon in the lower troposphere over the LFV, while southerly up-valley winds were evident in the tributary valleys to the north of the LFV. Such thermally driven flows are typical of ozone episodes in the LFV and are described in detail in Steyn and McKendry (1988). In Fig. 3a, ozone isopleths at 1500 PST, based on the surface observing network, show the typically observed pattern of low concentrations over the western LFV and relatively high concentrations downwind of the greater Vancouver source region. In the period 1200-1500 PST, the aircraft flight path included three legs within the LFV and three legs in the complex, forested terrain to the north of the LFV. Leg BC was within the Pitt Valley, a valley known to suffer from degraded air quality due to the northward advection of photochemically active air from the LFV (McKendry et al. 1997). At the northern end of Pitt Lake, the aircraft turned back toward $\mathrm{C}$ and began an 
ascent to approximately $2500 \mathrm{~m}$ (Fig. 3a). It then traveled northeast (leg CD) to the northern end of Harrison Lake, where it then descended back into the middle boundary layer and flew southward over Harrison Lake, making the first known observations of ozone in this locality (leg DE). Finally, the aircraft completed the sortie by traveling westward along the length of the LFV (legs EF and FA).

The northward flight leg AB showed mean ozone concentrations of $53 \mathrm{ppb}$ across the LFV (Fig. 3b). Concentrations measured by surface monitor at the entrance to Pitt Valley at this time $(\sim 1200$ PST) were about 51 ppb, in good agreement with those observed by the aircraft. Within the Pitt Valley (leg BC), concentrations rose steadily to a peak of $79 \mathrm{ppb}$ at the major bend in the lake and then declined again toward the northern end of the lake. This pattern has been observed in many flights into the Pitt Valley and suggests that the tributary valleys of the LFV may have the poorest air quality in the region. Possible mechanisms for the high concentrations observed include the effects of reduced surface deposition over water and the role of local thermotopographic circulations (McKendry et al. 1997).

As the aircraft climbed at the northern end of Pitt Lake, concentrations dropped from values of approximately $50 \mathrm{ppb}$ in the PBL to $35-40 \mathrm{ppb}$. At $2000 \mathrm{~m}$, as the aircraft headed toward Harrison Lake on leg CD, concentrations abruptly increased to $67 \mathrm{ppb}$ and remained in the range $65-70 \mathrm{ppb}$ until immediately prior to the descent into Harrison Lake at D, when they again dropped to $40 \mathrm{ppb}$.

The aircraft descent at $\mathrm{D}$ demonstrates the profiling capability of the system in complex terrain and also sheds light on the unusually high concentrations observed at an altitude of approximately 2500 on leg CD. The profile of ozone near D (Fig. 4) shows a distinct polluted layer from 2000-2250 m with concentrations twice those above and below. As observed in other studies of elevated layers in the LFV (McKendry et al. 1997) and the Los Angeles Basin (McElroy and Smith 1993), this layer of ozone aloft was associated with an inversion. If it is assumed that the layer was horizontally widespread, a likely explanation for the variations in ozone concentrations observed on leg $\mathrm{CD}$ is that the aircraft initially flew within the elevated layer. As it approached D it then briefly climbed out of the layer. On descent at D, the aircraft then encountered the layer again, giving the profile shown in Fig. 4.

Layers of ozone at this altitude have been previously observed over the LFV (McKendry et al. 1997), however, the mechanisms responsible for their formation are not clear. Possible causes include the venting of pollutants from the LFV into the lower troposphere along heated slopes (the "chimney effect") and plumes from biomass burning. The latter have been observed to have high ozone concentrations and travel considerable distances (Kirchhoff and Marinho 1994). A careful wind analysis and more comprehensive chemical measure-

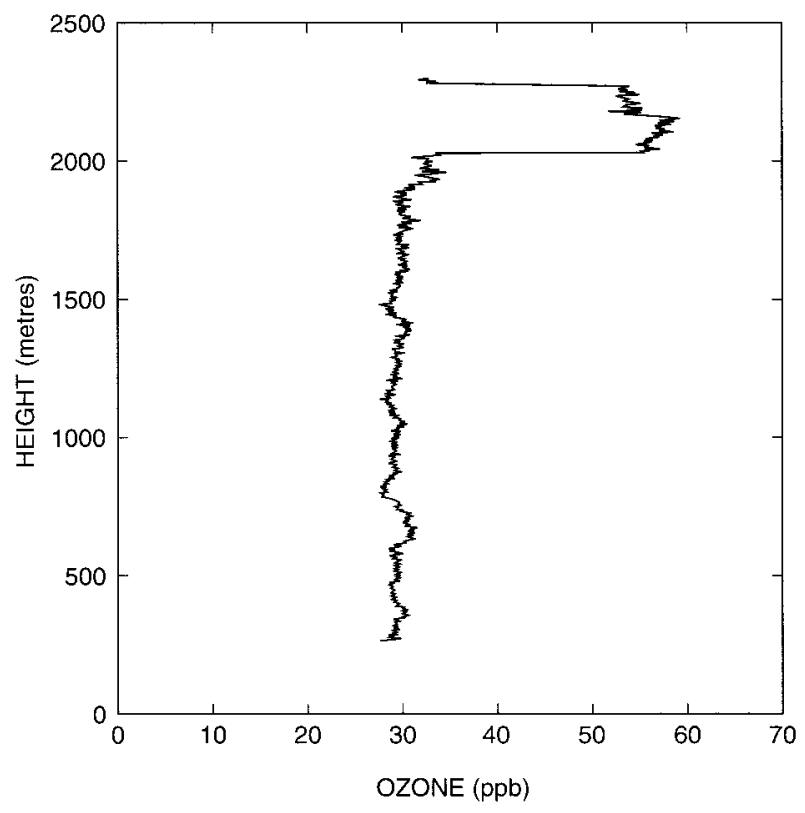

FIG. 4. Vertical profile at end of Harrison Lake in the vicinity of point D on 19 July 1995 during the flight shown in Fig. 4.

ments in such layers are required to determine their source.

As the flight continued southward (DE) within the PBL over Harrison Lake (Fig. 3a), concentrations remained near background levels (35-40 ppb) until the aircraft encountered a frontlike discontinuity in which concentrations increased abruptly to $70 \mathrm{ppb}$ in polluted air traveling northward past Long Island (Figs. 3a,b). Concentrations over the lake farther south exceeded 80 ppb and then dropped to $60 \mathrm{ppb}$ near Agassiz. This is the first known observation of the apparent transport of polluted air emanating from the LFV up Harrison Lake, a distance of approximately $110 \mathrm{~km}$ from Greater Vancouver. As in the case of the Pitt Valley, concentrations over the water of Harrison Lake were generally higher than those observed in the LFV.

On the return flight within the LFV (leg EF), observed concentrations in the PBL between Agassiz and Chilliwack were mostly in the range 70-80 ppb. From Chilliwack to the vicinity of Boundary Bay Airport (leg FG), concentrations decreased to the $60-70$ ppb range. These values appear quite consistent with the observed ground-level concentrations at approximately the same time (Fig. 3a).

This example demonstrates the extent to which aircraft can usefully extend observations into remote terrain beyond the surface monitoring network. In so doing, previously undocumented aspects of the regional distribution of pollutants and potentially important structures (such as elevated layers) may be identified. 


\section{c. Mass budget studies}

In addition to basic surveys of the horizontal and vertical distribution of ozone as described above, welldesigned aircraft observations using the OS-B-2 system can provide the basis for more fundamental research such as mass budget studies. In the latter technique, a simple mass budget model in which the boundary layer is treated as a slab (Lenschow et al. 1981) can be used to investigate the relative importance of photochemical processes, advection, and vertical fluxes in contributing to observed concentrations. For any atmospheric constituent, $\mathrm{S}\left(\mathrm{kg} \mathrm{m}^{-3}\right)$ assuming horizontal homogeneity for the mean and turbulent flux terms, and negligible mean vertical velocity the budget is

$$
\begin{aligned}
& \frac{\partial \overline{\mathrm{S}}}{\partial t}=Q_{s}-\bar{u} \frac{\partial \overline{\mathrm{S}}}{\partial x}-\frac{\partial \overline{\mathrm{S}^{\prime} w^{\prime}}}{\partial z}, \\
& \text { terms } 112403
\end{aligned}
$$

where $u$ is the mean wind aligned along the $x$ axis, $z$ is the vertical coordinate, and $Q_{s}$ is the source or sink of $\mathrm{S}$ (Lenschow et al. 1981). Therefore, for ozone, the rate change in a given volume at a fixed location (term 1) is comprised of ozone production or destruction within the volume (term 2), the mean horizontal advection (term 3), and the vertical flux divergence (term 4). With the exception of term 2, and if necessary with estimates of entrainment and deposition velocities, all the terms can be measured using the aircraft system described above.

Term 3 is easily calculated from ozone gradients over horizontal legs (e.g., FA in Fig. 3a) and using available wind data. With successive flights over the same flight leg, term 1 may also be estimated on the basis of the mean difference between successive time series. Finally, if the entire boundary layer is the volume considered, then flux divergence (term 4) is calculated on the basis of flux across the top of the mixed layer and deposition of ozone at the ground. Entrainment at the top of the boundary can be estimated on the basis of profile data derived from the aircraft (or tethered balloon), while deposition may be estimated on the basis of published or measured values.

\section{Conclusions}

A lightweight, fast-response chemiluminescent system for continuous monitoring of ozone and other meteorological variables from light aircraft has been described and tested in applications in the LFV, British Columbia. This system represents an efficient, affordable, and versatile alternative to more commonly used, but expensive, research configurations. Although mounted in a light aircraft in this application, it could be used on a range of light platforms (microlight, hang glider, drone), thereby permitting observations in environs inaccessible to larger, fast research aircraft (e.g., close to ground or slopes, and in complex terrain). As shown in the LFV, the system is a viable alternative to other methods of ozone profiling and is also particularly useful for routine aerial surveys of ozone distribution and process studies (e.g., mass budget analyses). In the single case discussed here, the system provided valuable insights into the horizontal and vertical distribution of ozone in the complex terrain surrounding the LFV. Finally, the system as described has the potential to be expanded to include other lightweight instruments. For example, Pisano et al. (1996) describe a lightweight $\mathrm{NO}_{2}$ sensor that could be integrated with the system. The addition of other chemical sensors would permit more rigorous analysis of mechanisms contributing to, and sources of, observed structures.

Acknowledgments. We are grateful to Laurence Armi, whose experience with a portable aircraft data acquisition system and generous advice provided a focus for the present work. We are also grateful to Dr. Wilfried Hans (GFAS) for advice on adapting the sonde to aircraft applications. The Greater Vancouver Regional District generously provided surface data and a monitor for calibration. Several students ably assisted in tethersonde operations. This work was supported by grants from the Natural Sciences and Engineering Research Council of Canada.

\section{REFERENCES}

Balsley, B. B., J. W. Birks, M. L. Jenson, K. G. Knapp, J. B. Williams, and G. W. Tyrrell, 1994: Ozone profiling using kites. Nature, 369, 23.

Beekman, M., and Coauthors, 1995: Intercomparison of tropospheric ozone profiles obtained by electrochemical sondes, a ground based lidar and an airborne UV-photometer. Atmos. Environ., 29, 1027-1042.

Clarke, J. F., and J. K. S. Ching, 1983: Aircraft observations of regional transport of ozone in the northeastern United States. Atmos. Environ., 17, 1703-1712.

Gregory, G. L., E. V. Browell, and L. S. Warren, 1988: Boundary layer ozone: An airborne survey above the Amazon Basin. J. Geophys. Res., 93, 1452-1468.

Güsten, G., G. Heinrich, R. W. H. Schmidt, and U. Schurath, 1992: A novel ozone sensor for direct eddy flux measurements. $J$. Atmos. Chem., 14, 73-84.

Kirchhoff, V. W. J. H., and E. V. A. Marinho, 1994: Layer enhancements of tropospheric ozone in regions of biomass burning. Atmos. Environ., 28, 69-74.

Kondo, Y., H. Kojima, N. Toriyama, Y. Morita, and M. Takagi, 1987: Chemiluminescent ozone instrument for aircraft observation. $J$. Meteor. Soc. Japan, 65, 795-802.

Lenschow, D. H., R. Pearson Jr., and B. B. Stankov, 1981: Estimating the ozone budget in the boundary layer by use of aircraft measurements of ozone eddy flux and mean concentration. J. Geophys. Res., 86, 7291-7297.

McElroy, J. L., and T. B. Smith, 1993: Creation and fate of ozone layers aloft in Southern California. Atmos. Environ., 27A, 19171929.

McKendry, I. G., 1994: Synoptic circulation and summertime groundlevel ozone concentrations at Vancouver, British Columbia. J. Appl. Meteor., 33, 627-641.

_ , and Coauthors, 1997: Elevated polluted layers and vertical 
down-mixing over the Lower Fraser Valley, B. C. Atmos. Environ., 31, 2135-2146.

Neu, U., T. Kunzle, and H. Wanner, 1994: On the relation between ozone storage in the residual layer and daily variation in near surface ozone concentrations-A case study. Bound.-Layer Meteor., 69, 221-247.

Pearson, R., Jr., and D. H. Stedman, 1980: Instrumentation for fast response ozone measurements from aircraft. Atmospheric Technology, Vol. 12, National Center for Atmospheric Research, 5155.

Pisano, J. T., J. W. Drummond, and D. R. Hastie, 1996: A lightweight $\mathrm{NO}_{2}$ instrument for vertical height profiles. J. Atmos. Oceanic Technol., 13, 400-406.

- I. G. McKendry, D. G. Steyn, and D. R. Hastie, 1997: Vertical nitrogen dioxide and ozone concentrations measured from a tethered balloon in the Lower Fraser Valley. Atmos. Environ., 31, 2071-2078.

Ritter, J. A., J. D. W. Barrick, C. E. Watson, G. W. Sasche, G. L. Gregory, B. E. Anderson, M. A. Woerner, and J. E. Collins Jr.,
1994: Airborne boundary layer flux measurements of trace species over Canadian boreal forest and northern wetland regions. J. Geophys. Res., 99 (D1), 1671-1685.

Schiff, H. A., A. Fried, and D. K. Killinger, Eds, 1994: Tunable Diode Laser Spectroscopy, lidar and DIAL techniques for environmental and industrial measurements. Proc. Int. Society for Optical Engineering Meeting, Atlanta GA. Int. Soc. for Optical Engineering, 362.

Schurath, U., W. Speuser, and R. Schmidt, 1991: Principle and application of a fast sensor for atmospheric ozone. Fresenius $J$. Anal. Chem., 340, 544-547.

Speuser, W., S. Sahand, and U. Schurath, 1989: A novel fast response chemiluminescent sonde for routine soundings of stratospheric ozone up to $1.5 \mathrm{mb}$. Ozone in the Atmosphere, R. D. Bojkov and P Fabian, Eds., Deepak, 747-750.

Steyn, D. G., and I. G. McKendry, 1988: Quantitative and qualitative evaluation of a three-dimensional mesoscale numerical model simulation of a sea breeze in complex terrain. Mon. Wea. Rev., 116, 1914-1926. 